\title{
Effectiveness of GFAP in Determining Neuronal Damage in Rats with Induced Head Trauma
}

\author{
Halil Ibrahim CIKRIKLAR ${ }^{1}$, Onur UYSAL ${ }^{2}$, Mehmet Ali EKICl ${ }^{3}$, Zuhtu OZBEK ${ }^{4}$, Didem TURGUT COSAN ${ }^{5}$, \\ Murat YUCEL ${ }^{1}$, Yusuf YURUMEZ ${ }^{1}$, Canan BAYDEMIR ${ }^{6}$ \\ ${ }^{1}$ Sakarya University, School of Medicine, Department of Emergency Medicine, Sakarya, Turkey \\ ${ }^{2}$ Eskisehir Osmangazi University, Vocational School of Health Services, Eskisehir, Turkey \\ ${ }^{3}$ Sevket Yilmaz Research and Training Hospital, Neurosurgery Clinic, Bursa, Turkey \\ ${ }^{4}$ Eskisehir Osmangazi University, School of Medicine, Department of Neurosurgery, Eskisehir, Turkey \\ ${ }^{5}$ Eskisehir Osmangazi University, School of Medicine, Department of Medical Biology, Eskisehir, Turkey \\ ${ }^{6}$ Eskisehir Osmangazi University, School of Medicine, Department of Biostatistics, Eskisehir, Turkey \\ This study was presented at the IX $\mathrm{X}^{\text {th }}$ National Emergency Medicine Congress, May 23-26, 2013, Turkey
}

\section{ABSTRACT}

AIM: To determine whether the serum level of glial fibrillary acidic protein (GFAP), an important indicator of neuron damage, correlates with the extent of tissue damage in the rat with induced head trauma and to obtain data in order to avoid unnecessary cranial computed tomography analyses.

MATERIAL and METHODS: Three-month-old male Sprague-Dawley rats were used. Rats were divided into 5 groups. The experimental head trauma model was examined in five groups $(n=8)$ as follows: The control group had no intervention; Group 1: Head trauma was induced by dropping a $25 \mathrm{mg}$ ball from a height of $20 \mathrm{~cm}$; Group 2: Head trauma was induced by dropping a $50 \mathrm{mg}$ ball from a height of $20 \mathrm{~cm}$; Group 3: Head trauma was induced by dropping a $50 \mathrm{mg}$ ball from a height of $80 \mathrm{~cm}$; Group 4 : Head trauma was induced by dropping a $100 \mathrm{mg}$ ball from a height of $80 \mathrm{~cm}$. Thus, according to the Newton's Law, respectively $0.05,0.1,0.2$ and $0.4 \mathrm{~N}$ trauma was created. Serum GFAP levels were analyzed and the damage to cerebral tissues was evaluated in all groups.

RESULTS: We determined that number of apoptotic cells and particularly the number of GFAP (+) protoplasmic astrocytes at the perilesional region of the cortex increased in association with the increased serum GFAP level as long as the severity of the trauma increased.

CONCLUSION: Serum GFAP concentration can be used as a marker of the severity of head trauma and traumatic brain injury. However, more animal studies are required to reflect this result in clinical practice.

KEYWORDS: Traumatic brain injury, Experimental, GFAP, Astrocyte, Rat

\section{INTRODUCTION}

$\longrightarrow$ ne common form of acute brain injury, traumatic brain injury (TBI), is the result of an outside force causing immediate mechanical disruption of brain tissue and delayed pathogenic events that collectively mediate wide- spread neurodegeneration and is still a major worldwide health problem $(2,33,44,50,51)$. TBI causes not only direct mechanical damage to the brain, but it also induces biochemical changes that lead to delayed neural cell loss. These biochemical changes are called secondary injury. The primary 
Cikriklar HI. et al: Effectiveness of GFAP in Traumatic Brain Injury

injury, due to direct or indirect impact to the brain, initiates a secondary injury process that spreads via multiple molecular mechanisms. Secondary injury mechanisms develop over a period of hours, and in the following days up to months after the primary injury. A growing number of studies have been designed to prevent secondary injury after TBI $(2,33)$.

Glial fibrillary acidic protein (GFAP) an intermediate filament protein specific for astrocytes has been frequently associated with reactive astrocytosis. Reactive astrocytosis, typified by astrocyte proliferation or astrocytic hypertrophy, is a major phenomenon of many pathological conditions of the central nervous system (CNS). Data from previous studies indicated that the increased local tissue GFAP immunoreactivity is a sensitive indicator of neuronal injury, and the increase in GFAP immunoreactivity is considered to be one sensitive marker of reactive astrocytosis. On the other hand, serum GFAP level increases when cerebral tissue or spinal cord cells are damaged due to trauma or disease $(9,15,46,54,57)$.

Experimental cranial trauma models try to reproduce the physiopathology, macroscopic and microscopic alterations in traumatic brain lesions in humans so as to study new therapeutic approaches. The weight-drop models use the gravitational forces of a free falling weight to produce a largely focal or diffuse brain injury. The impact of the free falling weight is delivered to the exposed skull in the rat and mouse, or the intact dura in the rat. When the impact is delivered to the exposed skull, generally soft tips (e.g. silicon-covered weights) reduce the risk of skull fractures $(45,50)$.

Cranial computed tomography (CCT) is an important device for the diagnosis of patients with head trauma. However, the indications of CCT are still debated with respect to the diagnosis of patients with minor head trauma $(10,20,21,24)$. Due to the high rate of pathological findings with CCT, the studies recommend routine CCT in patients with minor head trauma who have a history of amnesia and loss of consciousness (47). Particularly, exposure to radiation due to CCT under a particular age will lead to increased risk of malignancies and resultant mortality rate $(4,5)$.

In the current study, we aimed to determine whether serum levels of GFAP, an important indicator of neuron damage, correlate with the extent of tissue damage in the rat with induced head trauma and to obtain data in order to avoid unnecessary CCT analyses.

\section{MATERIAL and METHODS}

\section{Animals}

In this study, male Sprague-Dawley rats $(n=40)$ weighing $250 \pm 50 \mathrm{~g}$ were obtained from the Eskisehir Osmangazi University Experimental Research Center. They were used after 2 weeks of adaptation. The rats were housed in a polycarbonate cages in a temperature- $\left(21 \pm 10^{\circ} \mathrm{C}\right)$ and humidity (45-55\%)-controlled room that was maintained on a 12/12 reversed light-dark cycle and were fed with a standard rat chow (Oguzlar Yem, Eskisehir, Turkey) and allowed to drink ad libitum. The procedures involving animal care, surgery and sample preparation were approved by the Institutional Animal Care and Experiments Committee of Eskisehir Osmangazi University Faculty of Medicine, and the Guidelines laid down by the NIH in the US regarding the care and use of animals for experimental procedures were observed.

\section{Experimental Groups}

In this experimental study, the experimental head trauma model was examined in five groups $(n=8)$.

Control group: The rats of the control group had no intervention.

Group 1: Head trauma was induced by dropping a $25 \mathrm{mg}$ ball from a height of $20 \mathrm{~cm}$.

Group 2: Head trauma was induced by dropping a $50 \mathrm{mg}$ ball from a height of $20 \mathrm{~cm}$.

Group 3: Head trauma was induced by dropping a $50 \mathrm{mg}$ ball from a height of $80 \mathrm{~cm}$.

Group 4: Head trauma was induced by dropping a $100 \mathrm{mg}$ ball from a height of $80 \mathrm{~cm}$.

Thus, according to Newton's Law, respectively $0.05,0.1,0.2$ and $0.4 \mathrm{~N}$ trauma was created.

\section{Induction of Head Trauma}

Animals were sedated with intramuscular (i.m.) xylazine 10 $\mathrm{mg} / \mathrm{kg}$ (Rompun, Bayer llaç San, Istanbul) and anesthesia was induced with i.m. ketamine hydrochloride $50 \mathrm{mg} / \mathrm{kg}$ (Ketalar, Eczacibasi llaç San, Istanbul). Head trauma was induced using the modified version of the model that was described by Marmarou et al. (34). Fracture of the skull or death secondary to trauma were excluded. Blood was drawn and cerebral tissue specimens were biopsied for biochemical and histological analyses, respectively, at 2 hours following the induction of trauma, and all animals were sacrificed.

\section{Detection of Serum GFAP Levels}

Venous blood samples were collected from the rats at the time of decapitation. The blood was centrifuged at $3,000 \mathrm{rpm}$ at $4^{\circ} \mathrm{C}$ for 10 minutes, and the serum was stored at $-80^{\circ} \mathrm{C}$ until analysis. GFAP levels were detected in the serum by the Rat GFAP ELISA kit (Eastbiopharm, Hangzhou). Standards were added to the samples in the wells. Antibodies labeled with enzyme were added and the plate was incubated for 60 minutes at $37^{\circ} \mathrm{C}$. Then plate was washed five times and chromogen solutions were added. It was incubated 10 minutes at $37^{\circ} \mathrm{C}$ and stop solution added into wells. Optical density (OD) was measured under the $450 \mathrm{~nm}$ wavelength with a microplate reader (LabSystems, UV/Vis. Spectrum Finstruments ${ }^{\text {TM }}$ Multiskan Model 347 Finland).

\section{Histological Examinations}

Hematoxylin and Eosin (H\&E) staining: Cerebral tissue were carefully and rapidly exposed and fixed with formalin solution with neutral buffer. After fixation, the tissues were embedded in paraffin and serial sections $(4 \mu \mathrm{m})$ were taken. Sections were stained with $\mathrm{H} \& \mathrm{E}$ for histological analyses, with TUNEL for apoptosis, and with GFAP immunohistochemical staining 
to determine the number of protoplasmic astrocytes. Images were obtained with the Olympus BX-61 microscope attached a DP70 digital camera. The histological analyses of the brain injury were semi-quantitatively scored by light microscopy. The severity of the histopathological changes and neuronal changes were scored as follows: (0) no injury; (1) mild; (2) moderate and (3) severe/diffuse. The examination of the histological changes consisted of evaluating the following parameters: vascular congestion, intraparenchymal hemorrhage, inflammation, edema and gliosis. The examination of the neuronal degenerative changes consisted of the evaluation of the following: nuclear pyknosis, nuclear hyperchromasia, cytoplasmic eosinophilia, and axonal swelling $(1,7,19,23,29,30,44,53)$.

TUNEL staining: For in situ detection of DNA fragmentation in paraffin-embedded tissue sections, the TUNEL method was performed in deparaffinized $4-\mu \mathrm{m}$-thick sections using the ApopTag $®$ peroxidase kit (Cat. no.S7101; Chemicon International-ApopTag Plus Peroxidase Kits, USA). For analysis of TUNEL (+) motor neurons located at the perilesional region of the cortex, two independent observers evaluated 25 optical fields for each 50 sections per animal chosen randomly using a $\times 40$ ocular micrometer by light microscopy and the median $25 \%-75 \%$ percentiles were calculated $(1,28,44)$.

GFAP immunohistochemistry (Avidin-Biotin Method): To identify protoplasmicastrocytosis, GFAP immunohistochemical staining was performed on formalin-fixed, paraffin-embedded brain tissue. Three sections from each brain were examined. In each case, $4 \mu \mathrm{m}$ thick serial paraffin sections were obtained on Poly-L-Lysine coated slides. For analysis of GFAP (+) protoplasmic astrocytes located at the perilesional region of the cortex, two independent observers evaluated 25 optical fields for each 50 sections per animal chosen randomly using a x40 ocular micrometer by light microscopy and median $25 \%-75 \%$ percentiles were calculated $(19,29,30,44,46,51,53,54,57)$.

\section{Statistical Analysis}

Data were expressed as count (percentage), mean \pm standard deviation (SD) or the median and the interquartile range (IQR, range from the $25^{\text {th }}$ to the $75^{\text {th }}$ percentile). Normal distribution for numeric variables was evaluated by the KolmogorovSmirnov test. The difference between the groups was evaluated by using One Way ANOVA and Tukey's Multiple Comparison Test, Kruskal-Wallis One-Way ANOVA and Dunn's Multiple Comparison Test. IBM SPSS Statistics 20.0 statistical package (SPSS Inc., Chicago, IL, USA) was used for the evaluation of data. $P$ value of $<0.05$ was considered to be adequate to reject the null hypothesis.

\section{- RESULTS}

\section{Biochemical Analysis}

Mean values of serum GFAP levels were $0.3421 \pm 0.12208$ $\mathrm{ng} / \mathrm{ml}$ for the control group, $0.3692 \pm 0.21728 \mathrm{ng} / \mathrm{ml}$ for group $1(20 \mathrm{~cm} / 25 \mathrm{~g}), 0.5345 \pm 0.16875 \mathrm{ng} / \mathrm{ml}$ for group 2 $(20 \mathrm{~cm} / 50 \mathrm{~g}), 0.5824 \pm 0.27226 \mathrm{ng} / \mathrm{ml}$ for group $3(80 \mathrm{~cm} / 50$ g), $0.6337 \pm 0.23494 \mathrm{ng} / \mathrm{ml}$ for group $4(80 \mathrm{~cm} / 100 \mathrm{~g})$. In comparison of mean values of serum GFAP levels, the values were statistically significantly different between all groups $(p=0.029)$. In comparison of the study groups, a statistically significant difference was observed between group 1 and both groups $3(p=0.049)$ and $4(p=0.016)$. Based on our findings, we observed a relationship between serum GFAP levels and the severity of the trauma (Table I).

\section{Histological Results}

Based on H\&E staining, histopathological changes were examined on the perilesional region of the cerebral cortex, and a statistically significant difference was observed between all study groups and the control group with respect to vascular congestion, intraparenchymal hemorrhage, inflammation, edema and gliosis $(p<0.05)$. In the comparison of study groups, no statistically significant difference was observed (Table II).

A statistically significant difference was observed between the control group and all study groups with respect to the neural degenerative changes $(p<0.05)$. In comparison of study groups, a statistically significant difference was observed between group 4 and groups 1, 2, 3 in terms of nuclear pyknosis, nuclear hyperchromasia and cytoplasmic eosinophilia $(p<0.05)$. A statistically significant difference was observed between the control group and all study groups only with respect to the axonal swelling $(p<0.05)$ (Table II) (Figure 1A-D).

A statistically significant difference was observed between the control group and all study groups when the TUNEL (+) motor neurons were counted in the perilesional region of the cortex $(p<0.05)$. In comparison of study groups, a statistically significant difference was observed between group 4 and groups 1, 2, 3 in terms of TUNEL $(+)$ motor neurons $(p<0.05)$. Based on our data, it is concluded that there is positive relationship between the severity of the trauma and a significant increase in the number of apoptotic cells (Table III) (Figure 2A, B).

A statistically significant difference was observed between the control group and all study groups when the GFAP (+) protoplasmic astrocytes were counted in the perilesional region of the cortex $(p<0.05)$. In the comparison of study groups, a statistically significant difference was observed between group 4 and groups 1, 2, 3 in terms of GFAP (+) protoplasmic astrocytes $(p<0.05)$.

Based on our data, it is concluded that there is positive relationship between the severity of the trauma and significant increase in the number of GFAP (+) protoplasmic astrocytes (Table IV) (Figures 3A-D, 4A-D).

\section{DISCUSSION}

\section{The Relationship Between Serum GFAP Levels and TBI}

GFAP is one of the strongest diagnostic indicators at the early period of post-TBI and a good indicator of the mortality following TBI $(3,42)$. Many studies have demonstrated that most patients with head trauma (73-93\%) are referred to the healthcare facility within the first six hours $(20,24,36)$. Therefore, 
the blood GFAP level can be an important diagnostic indicator for most patients with head trauma. Particularly, studies were conducted to investigate the diagnostic efficiency of GFAP in severe head trauma and it was found that serum GFAP levels were related with the severity of trauma and the mortality $(32,39,58)$.

Lumpkins et al. (32) conducted a study where adults with severe head trauma had remarkable decrease in the serum GFAP levels as of the second day. They determined that the high GFAP level, which persisted at the second day, was significantly related with the mortality. However they suggest that baseline GFAP levels were not related with mortality. Pelinka et al. (39) reported that blood GFAP level had been high for several days in patients with severe head trauma, who could not survive, and that blood GFAP level decreased within the first 36 hours in survivors. In a clinical study which included patients with severe head trauma, Zurek and Fedora (58) determined that post-TBI serum GFAP levels were higher

Table I: Evaluation of the Venous Blood GFAP Concentration for All Groups

\begin{tabular}{lcccc}
\hline Groups & Newton & $\mathbf{n}$ & $\begin{array}{c}\text { Serum GFAP Concentration }(\mathbf{n g} / \mathbf{m l}) \\
\text { (Mean } \pm \text { St. Deviation) }\end{array}$ & $\mathbf{f}(\mathbf{p})$ \\
\hline Control Group & 0 & 8 & $0.3421 \pm 0.12208$ & \\
\hline Group 1 $(20 \mathrm{~cm} / 25 \mathrm{~g})$ & 0.05 & 8 & $0.3692 \pm 0.21728$ & 3.075 \\
\hline Group 2 $(20 \mathrm{~cm} / 50 \mathrm{~g})$ & 0.1 & 8 & $0.5345 \pm 0.16875$ & $\left(0.029^{\mathrm{a}, \mathrm{b}, \mathrm{c}, \mathrm{d}}\right)$ \\
\cline { 1 - 4 } Group $3(80 \mathrm{~cm} / 50 \mathrm{~g})$ & 0.2 & 8 & $0.5824 \pm 0.27226$ & \\
\hline Group $4(80 \mathrm{~cm} / 100 \mathrm{~g})$ & 0.4 & 8 & $0.6337 \pm 0.23494$ & \\
\hline
\end{tabular}

f: One-way Analysis Of Variance

a: The statistical difference resulting from the comparison of the Control Group and Group 3

b: The statistical difference resulting from the comparison of the Control Group and Group 4

c: The statistical difference resulting from the comparison of Group 1 and Group 3

d: The statistical difference resulting from the comparison of Group 1 and Group 4

Table II: Histological Assessment of Motor Neurons in the Perilesional Cortex (Median (25\%-75\% Percentiles))

\begin{tabular}{|c|c|c|c|c|c|c|c|}
\hline \multirow[b]{2}{*}{ Groups } & & \multicolumn{6}{|c|}{ Median (25\%-75\% percentiles) } \\
\hline & & $\begin{array}{l}\text { Control } \\
\text { Group }\end{array}$ & $\begin{array}{c}\text { Group } 1 \\
(20 \mathrm{~cm} / 25 \mathrm{~g})\end{array}$ & $\begin{array}{c}\text { Group 2 } \\
(20 \mathrm{~cm} / 50 \mathrm{~g})\end{array}$ & $\begin{array}{c}\text { Group } 3 \\
(80 \mathrm{~cm} / 50 \mathrm{~g})\end{array}$ & $\begin{array}{c}\text { Group } 4 \\
(80 \mathrm{~cm} / 100 \mathrm{~g})\end{array}$ & $H(p)$ \\
\hline \multirow{5}{*}{$\begin{array}{l}\text { Histopathological } \\
\text { Changes }\end{array}$} & $\begin{array}{l}\text { Vascular } \\
\text { Congestion }\end{array}$ & $0(0-0)$ & $3(3-3)$ & $3(3-3)$ & $3(3-3)$ & $3(3-3)$ & $33.253(<0.001)^{\mathrm{a}}$ \\
\hline & $\begin{array}{l}\text { Intraparenchymal } \\
\text { Hemorrhage }\end{array}$ & $0(0-0)$ & $1(1-1)$ & $1(1-1)$ & $1(1-1.5)$ & $1(1-2)$ & $29.743(<0.001)^{\mathrm{a}}$ \\
\hline & Inflammation & $0(0-0)$ & $1(1-1)$ & $1(1-2)$ & $1.5(1-2)$ & $2(1-2.5)$ & $26.072(<0.001)^{\mathrm{a}}$ \\
\hline & Edema & $0(0-0)$ & $2.5(2-3)$ & $3(3-3)$ & $3(3-3)$ & $3(3-3)$ & $31.114(<0.001)^{\mathrm{a}}$ \\
\hline & Gliosis & $0(0-0)$ & $2.5(2-3)$ & $3(2.5-3)$ & $2.5(2-3)$ & $3(3-3)$ & $24.561(<0.001)^{\mathrm{a}}$ \\
\hline \multirow{4}{*}{$\begin{array}{l}\text { Neuronal } \\
\text { Degenerative } \\
\text { Changes }\end{array}$} & Nuclear Pyknosis & $0(0-0)$ & $2(2-2)$ & $2(1-2)$ & $2(2-2)$ & $3(3-3)$ & $33.993(<0.001)^{a, b, b, d}$ \\
\hline & $\begin{array}{l}\text { Nuclear } \\
\text { Hyperchromasia }\end{array}$ & $0(0-0)$ & $2(2-2)$ & $2(1-2)$ & $2(2-2)$ & $3(3-3)$ & $33.993(<0.001)^{a, b, c, d}$ \\
\hline & $\begin{array}{l}\text { Cytoplasmic } \\
\text { Eosinophilia }\end{array}$ & $0(0-0)$ & $2(2-2)$ & $2(1-2)$ & $2(2-2)$ & $3(3-3)$ & $32.160(<0.001)^{\mathrm{a}, \mathrm{b}, \mathrm{c}, \mathrm{d}}$ \\
\hline & Axonal Swelling & $0(0-0)$ & $2(2-3)$ & $2.5(2-3)$ & $3(3-3)$ & $3(3-3)$ & $29.824(<0.001)^{\mathrm{a}}$ \\
\hline
\end{tabular}

no injury: 0, mild: 1, moderate: 2 , and severe/diffuse: 3

H: Kruskal-Wallis variance analysis

a: The statistical difference resulting from the comparison of the control group and all study groups

b: The statistical difference resulting from the comparison of the group 1 and group 4

c: The statistical difference resulting from the comparison of group 2 and group 4

d: The statistical difference resulting from the comparison of group 3 and group 4 


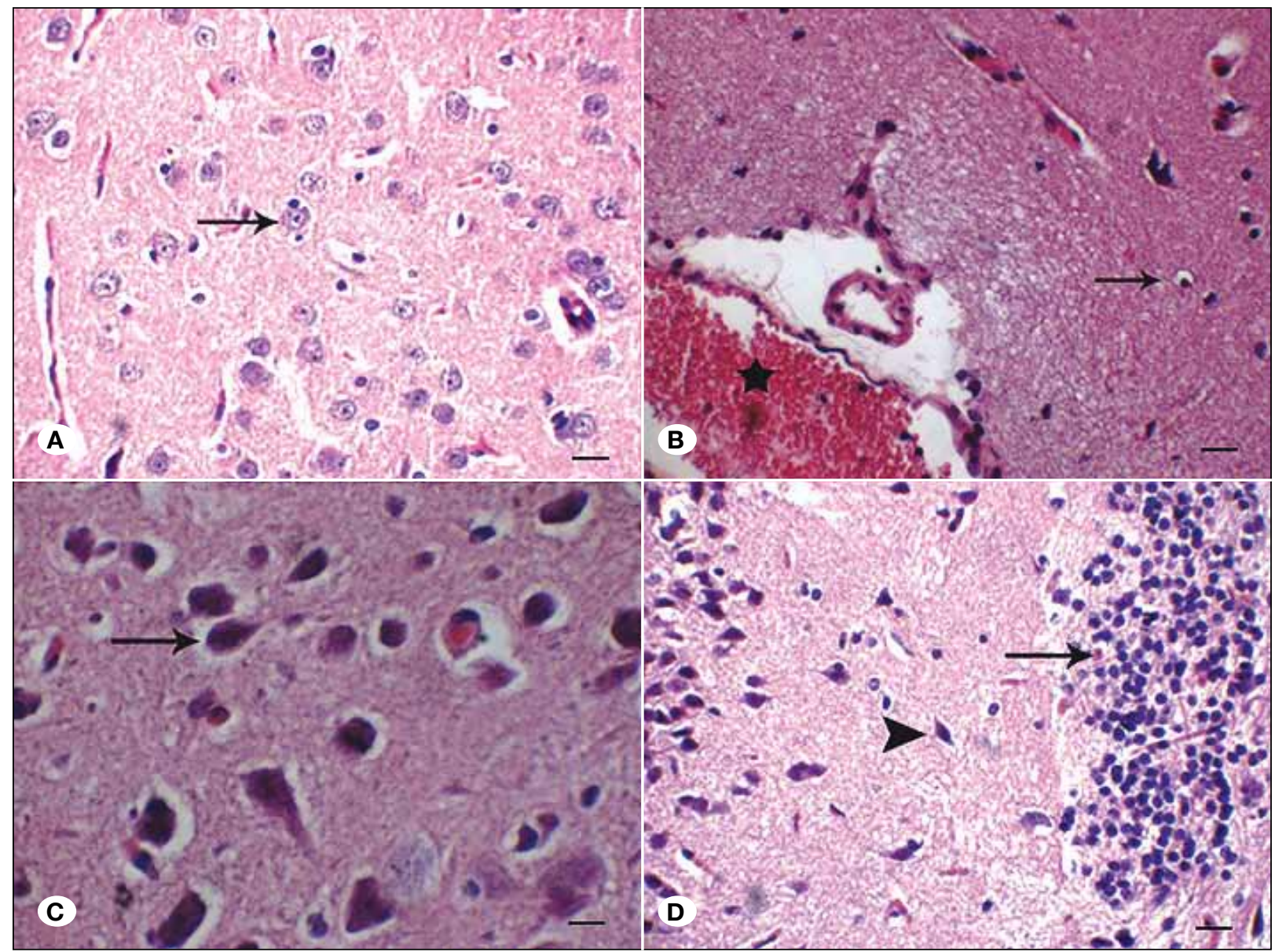

Figure 1: Neuronal morphology indicated by hematoxylin-eosin staining. A) Histological appearances of normal brain parenchyma in control group. Neurons have a large, round nucleus with a single prominent nucleolus (arrow). (H\&E, Scale Bar 20 um.), B) Congestion (asterisk), edema and pyknosis in group $4(80 \mathrm{~cm} / 100 \mathrm{~g})$. Neurons show severe shrunken perikarya and nuclei (arrow). (H\&E, Scale Bar $20 \mu \mathrm{m})$, C) Edema and pyknosis in group $4(80 \mathrm{~cm} / 100 \mathrm{~g})$. Scattered clusters of angular ischemic neurons with pyknotic nuclei and vacuolization (edema) in the neuropil (arrow). (H\&E, Scale Bar $10 \mu \mathrm{m})$, D) Necrosis and reactive gliosis in group 3 (80 cm/50 g). Most neurons are severe shrunken (arrow head) and focal reactive gliosis (arrow) (H\&E, Scale Bar $20 \mu \mathrm{m})$.
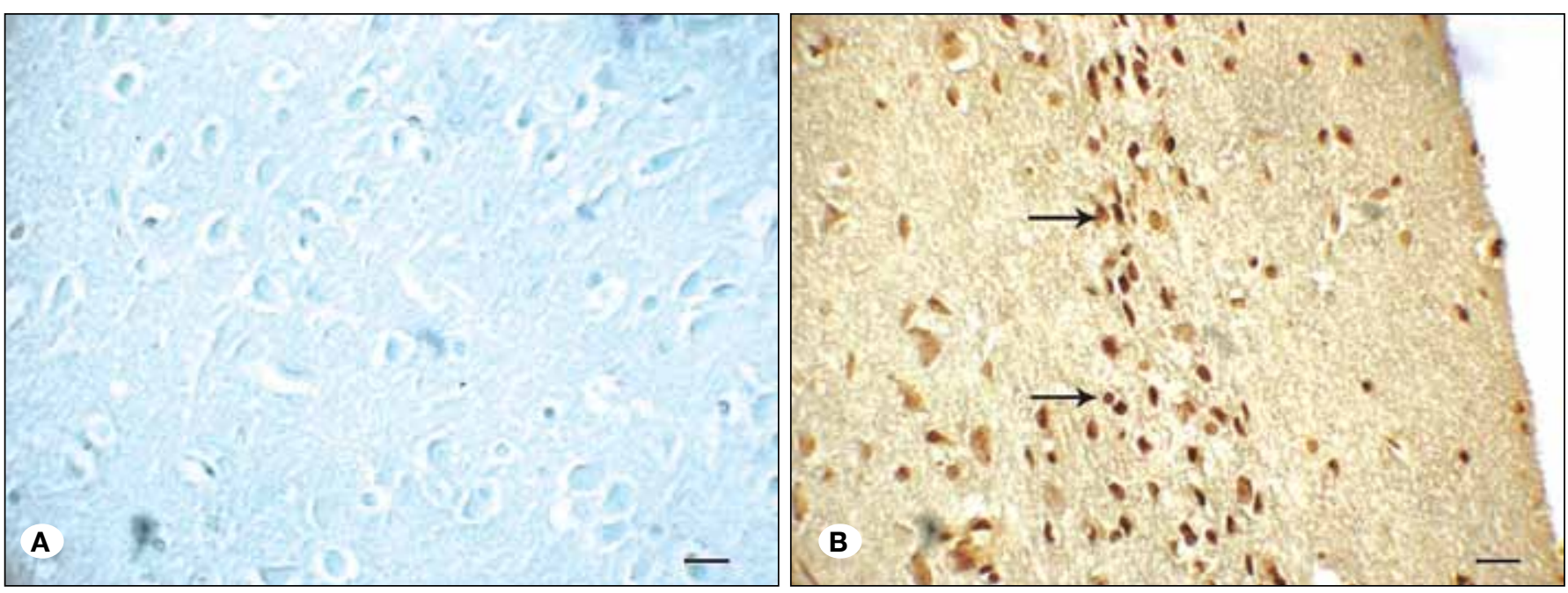

Figure 2: TUNEL immunohistochemistry staining in the perilesional region of the cortex of the brain following TBI. A) Control group rats showing few/not TUNEL(+) apoptotic cells. (TUNEL, Scale Bar $20 \mu \mathrm{m})$, B) Group $4(80 \mathrm{~cm} / 100 \mathrm{~g})$ rats showing more TUNEL(+) apoptotic cells (arrow) than control and other groups. (TUNEL, Scale Bar $20 \mu \mathrm{m}$ ). 
Cikriklar HI. et al: Effectiveness of GFAP in Traumatic Brain Injury

Table III: The Total Number of Tunel (+) Motor Neurons in the Perilesional Cortex in All Groups (Median (25\%-75\% Percentiles))

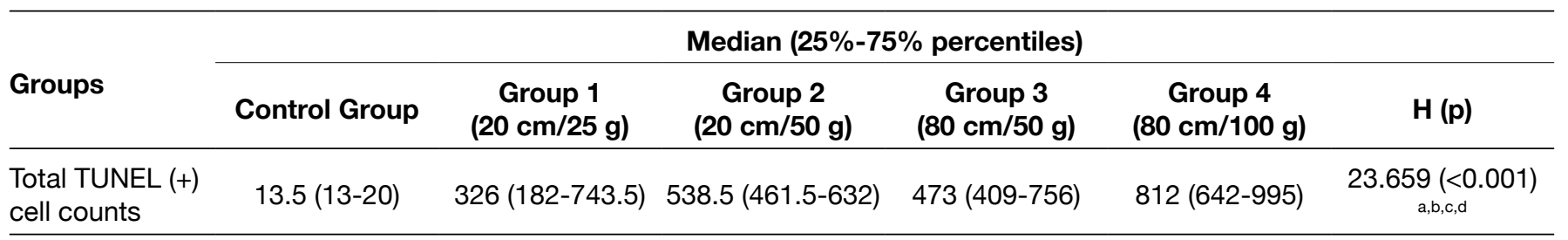

no injury: 0 , mild: 1 , moderate: 2 , and severe/diffuse: 3

H: Kruskal-Wallis variance analysis

a: The statistical difference resulting from the comparison of the control group and all study groups

b: The statistical difference resulting from the comparison of group 1 and group 4

c: The statistical difference resulting from the comparison of group 2 and group 4

d: The statistical difference resulting from the comparison of group 3 and group 4

Table IV: The Total Number of GFAP (+) Protoplasmic Astrocytes in the Perilesional Cortex in All Groups (Median (25\%-75\% Percentiles))

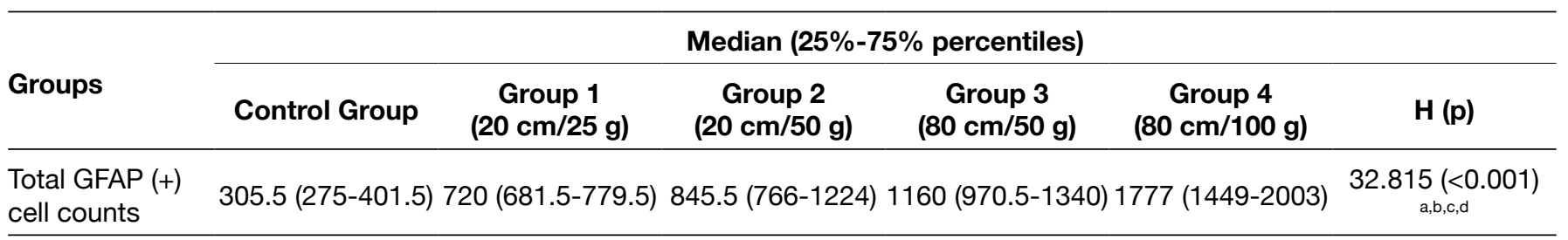

no injury: 0, mild: 1, moderate: 2 , and severe/diffuse: 3

H: Kruskal-Wallis variance analysis

a: The statistical difference resulting from the comparison of the control group and all study groups

b: The statistical difference resulting from the comparison of group 1 and group 4

c: The statistical difference resulting from the comparison of group 2 and group 4

d: The statistical difference resulting from the comparison of group 3 and group 4

and continued to be high for many days in patients who were associated with mortality and the levels were lower for the patient who achieved survival.

Wiesmann et al. (52) enrolled 60 patients who had Glasgow Coma Scale (GCS) scores ranging from 3 to 15. In the study, they found that blood GFAP levels were significantly high within the first 6 hours, while a remarkable decrease was noted in blood samples that were drawn after 6 hours. Missler et al. (37) conducted a study where blood GFAP level was investigated in patients with severe head trauma who had a GCS score $\leq 6$. In this study, the GFAP level was high in all blood samples, which were drawn within three hours following the injury, while the GFAP level was high in $56 \%$ of samples which were drawn at 4-6 hours and the level was high only in $10 \%$ of samples which were drawn after 7 hours. The blood GFAP level rapidly decreased within the first six hours following TBI. Therefore, in our study blood was drawn for biochemical analyses at 2 hours following the induction of trauma. Taking all these studies into account, serum GFAP levels increased early in patients with TBI and this increase seems to be associated with mortality. The rise and fall of serum GFAP levels after the first six hours show that serum GFAP measurement can be used at an early stage, and our results also support this. Indeed, in our study, serum GFAP levels have been shown to increase at the second hour in rats with head trauma and this increase correlates with the severity of the trauma. These findings are compatible with the literature. Therefore the blood
GFAP level can be a good indicator of neurological outcomes for patients who present within first two hours following the head trauma.

\section{The Histopathological Changes in TBI}

TBl is a result of an outside force causing immediate mechanical disruption of brain tissue and delayed pathogenic events. TBI initiates a complex series of neurochemical signalling events. These pathological changes are mediated, at least in part, by glutamate excitotoxicity, inflammation and increased bloodbrain barrier permeability leading to numerous sequela that include neuronal hyperactivity, increased cellular vulnerability, edematous states, cellular dysfunction and consequent apoptotic and necrotic cell death $(2,6,23,51)$. Brain trauma causes cerebral edema that results from a combination of a loss of the integrity of the blood brain barrier and excessive accumulation of ions and water within the cells (8).

To better understand the pathological mechanisms underlying $\mathrm{TBI}$ and to develop strategies and interventions to limit the secondary damage, the use of rodent models is essential. A number of rodent models to induce brain trauma have been described; however, none of them covers the entire spectrum of events that might occur in TBI (51). Of these, the most commonly used are weight-drop injury, fluid percussion injury, and cortical contusion injury. The weight-drop models use the gravitational forces of a free falling weight to produce a largely focal or diffuse brain injury. The severity of head trauma 


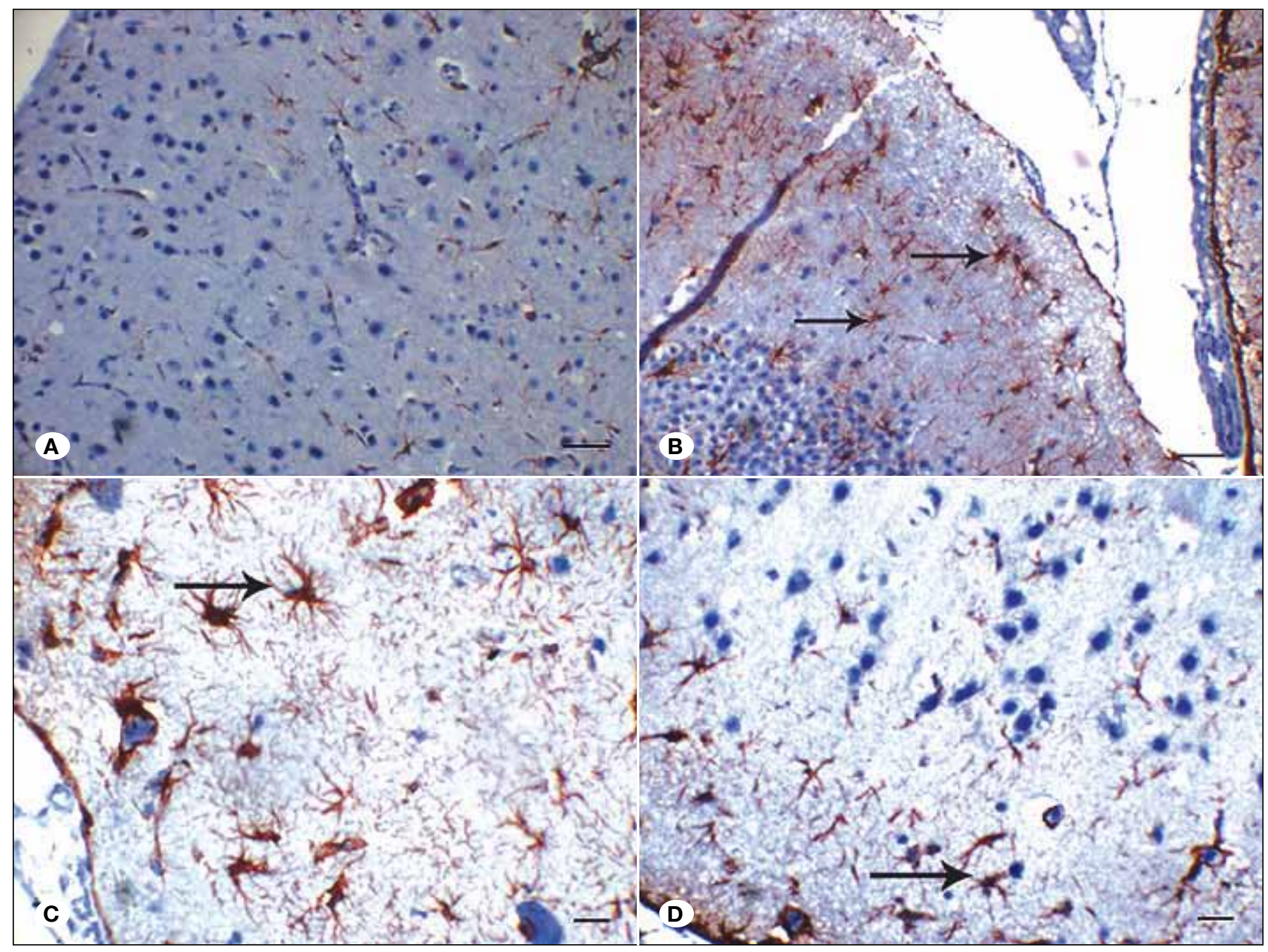

Figure 3: Immunohistochemistry for GFAP in the perilesional region of the cortex of the brain following TBI. A) Appearance of protoplasmic astrocytes in control group. Note that the territories of astrocyte processes do not overlap and that many astrocytes do not express detectable levels of GFAP. (GFAP, Scale Bar $50 \mu \mathrm{m}$ ), B) Severe diffuse reactive astrogliosis with pronounced up regulation of GFAP expression, astrocyte hypertrophy, astrocyte proliferation and pronounced overlap of astrocyte processes resulting in disruption of individual astrocyte domains in group $4(80 \mathrm{~cm} / 100 \mathrm{~g})$. (GFAP, Scale Bar $50 \mu \mathrm{m})$, C) Severe diffuse reactive astrogliosis, astrocyte hypertrophy, astrocyte proliferation and pronounced overlap of astrocyte processes resulting in disruption of individual astrocyte domains in group $4(80 \mathrm{~cm} / 100 \mathrm{~g})$. (GFAP, Scale Bar $20 \mu \mathrm{m})$, D) Moderately reactive astrogliosis in which most (if not all) protoplasmic astrocytes have up regulated expression of GFAP and exhibit cellular hypertrophy, but with preservation of individual astrocyte domains and without pronounced overlap of astrocyte processes in group 3 (80 cm/50 g).(GFAP, Scale Bar $20 \mu \mathrm{m})$.

can be varied by using different weights and/or heights of the weight-drop (50). Weight loss models to produce closed head traumas have been used to create diffuse lesions through the energy transfer between the weight in free fall and the experimental animal head. Marmarou et al. (34) have described histopathological alterations observed on a weight drop model in that $450 \mathrm{mg}$ weight falls onto the metallic disc fixed to the intact animal head supported by a foam bed. This model has been shown to produce graded brain injury in rodents depending upon the mass and the height from which the brass weight is released. As for histopathological findings, petechial hemorrhages could be observed in the brain stem. Microscopically, the model has produced generalized lesions in neurons, axons and microvasculature. The neuronal lesion was observed bilaterally in the brain cortex. Cerebral edema, mainly presenting as astrocytic periciliary swelling, was also been observed in these cortex areas and in the brain stem $(34,45)$. In the current study, we had modified the TBI model of Marmarou et al. (34). There are several possible mechanisms linking an episode of TBI to later development of neurodegenerative disease, such as neuronal loss, persistent inflammation and cytoskeletal pathology. The pathology of $\mathrm{TBI}$ is multifaceted and may include contusion, hemorrhage and diffuse axonal damage. Cerebral edema is an additional acute complication of brain injury and results from excess accumulation of water in the intra- and extracellular 


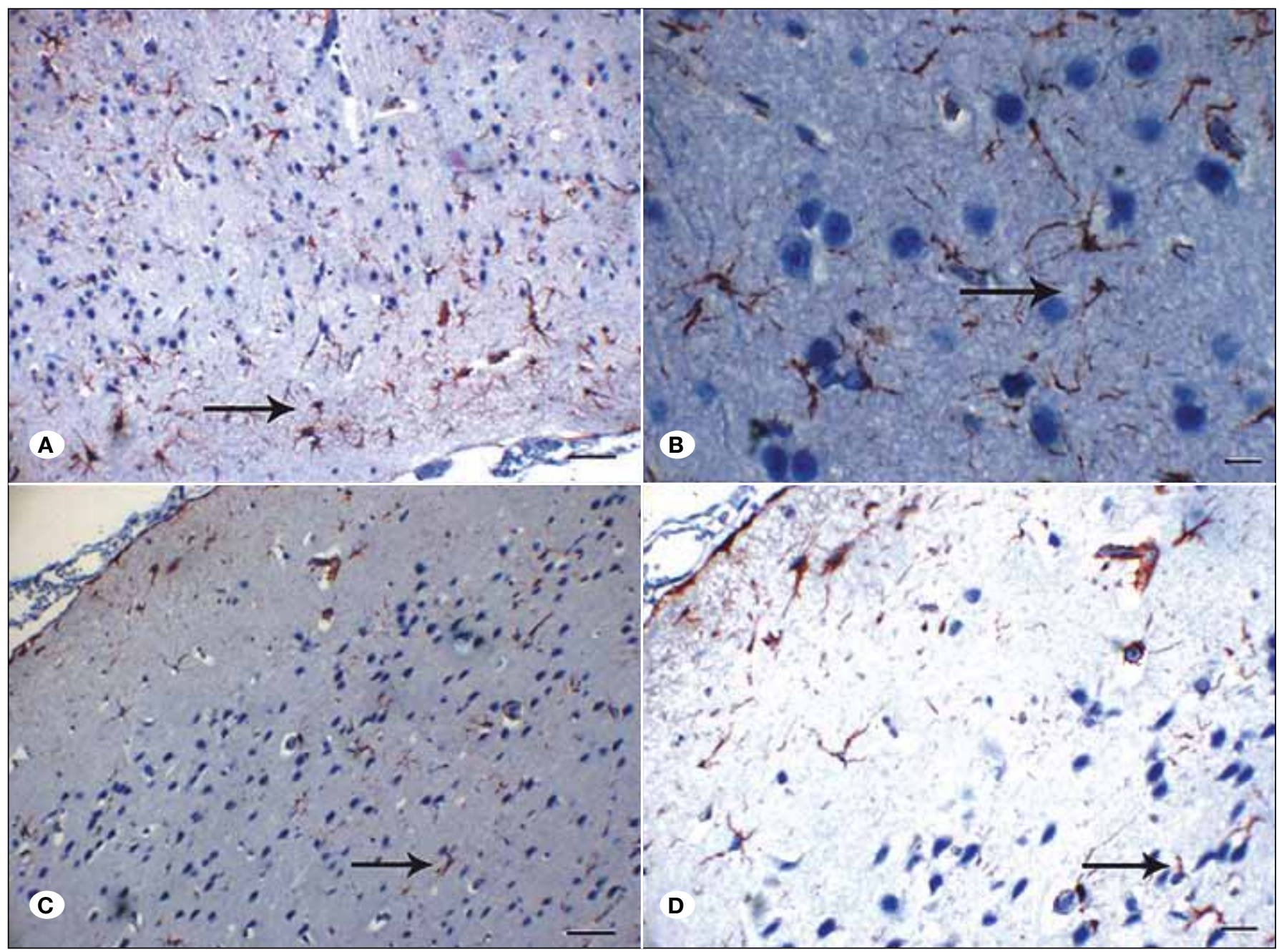

Figure 4: A) Mildly reactive astrogliosis in group $2(20 \mathrm{~cm} / 50 \mathrm{~g})$.(GFAP, Scale Bar $50 \mu \mathrm{m})$, B) Mildly reactive astrogliosis in group 2 (20 $\mathrm{cm} / 50 \mathrm{~g}$ ). Note that the territories of protoplasmic astrocyte processes do not overlap (arrow) and that many astrocytes do not express detectable levels of GFAP. (GFAP, Scale Bar $10 \mu \mathrm{m})$, C) Mildly reactive astrogliosis in group $1(20 \mathrm{~cm} / 25 \mathrm{~g})$. (GFAP, Scale Bar $50 \mu \mathrm{m}$ ), D) Mildly reactive astrogliosis in group $1(20 \mathrm{~cm} / 25 \mathrm{~g})$. Note that many protoplasmic astrocytes do not express detectable levels of GFAP (arrow). (GFAP, Scale Bar $20 \mu \mathrm{m}$ )

space $(18,22,25,27)$. Our histopathological findings, such as vascular congestion, hemorrhage, edema and axonal swelling, are consistent with the findings of authors. Williams et al. (53) had demonstrated that two distinct and divergent temporal neuro-inflammatory profiles were also captured with the penetrating ballistic brain injury model. The first is the rapid neuro-inflammatory response within the core lesion characterized by a strong gliotic response coupled with mass infiltration of peripheral inflammatory cells. In contrast, the neuro-inflammatory response in the thalamus involved primarily a gliotic response void of the marked infiltration of peripheral inflammatory cells as seen in the primary lesion (53). Acute edema developed after moderate diffuse TBI. In our study, vascular congestion and hemorrhage was identified in the cerebral cortex at microscopic level. Inflammation and hemorrhages were identified in the cerebral cortex. Lesions demonstrated necrotic neurons, astrocytes, and vasogenic edema.

\section{The Role of Apoptosis in TBI}

Neuronal cell death due to impact showed features of both necrosis and apoptosis, similar to previously developed models of closed head injury (6). Apoptosis is a generalized form of cell death distinct from necrosis. It occurs under physiological as well as pathophysiological conditions. Apoptosis also plays an important role in neurodegenerative, myeloplastic and ischemic nervous system disorders and likely contributes to cell death after TBI $(18,22,25,27)$. There are few reports of apoptosis after focal contusion induced by controlled cortical impact. The first demonstration of apoptosis in controlled cortical impact that included measurements at $6 \mathrm{~h}, 24 \mathrm{~h}$ and 2 weeks post injury provides data for the presence of apoptosis at three different time points. Apoptosis induced by trauma is an early and persistent process, present for at least 2 weeks after injury. Apoptosis continues at times when necrosis is presumed to have ceased (25). In the current study, the number of apoptotic cells significantly increased in the perilesional 
cortex area at 2 hours following TBI. We also found increased count of apoptotic cells in addition to the increased weight. There were also shrunken neurons associated with perineuronal vacuolation in cortical areas after injury. Neuronal necrosis resulted in neuronal cytoplasmic eosinophilia with pyknotic nuclei. Necrosis significantly increased in the group 4, while no significant increase was observed among other study groups. It is attractive to speculate that more severely damaged neurons undergo necrosis and less severely damaged neurons take the apoptotic pathway. The location of apoptotic cells along the boundary zone of contusion also suggests that apoptosis contributes to the expansion of TBI.

\section{The Role of Astrocytes in TBI}

Brain injury induces activation of resident glial cells that participate in the inflammatory response. Astrocytes are known to be a source of pro-inflammatory cytokines and in the advanced stages of injury progression form a glial scar inhibitory to neural regeneration $(33,53)$. Astrocytes play a major role in restoring homeostasis to the damaged brain. In general, they are more resistant than neurons during periods of energy failure or following toxic insult. However, overextension of the protective capability of the astroglial response will ultimately lead to cell death. Direct astrocytic malfunction or loss of viability has been coupled to the subsequent death of neurons within the surrounding environment. The acute neuroinflammatory response occurred very rapidly post-injury with a peak up-regulation of inflammatory genes occurring on the order of several hours before that reported for similar responses in focal ischemic injury models. Reactive gliosis, characterized by hypertrophy and proliferation of astroglial cells, is a common phenomenon in the CNS following tissue destruction induced by degenerative diseases or by trauma. On the other hand, the formation of a glial scar by activated astrocytes may protect the still intact tissue from secondary lesions. Hypertrophic astrocytes are thought to play an important role in the healing phase after tissue destruction $(14,23,45,54)$. Glial reactivity surrounding the primary lesion, as indicated from the presence of highly ramified and strongly immunoreactive cell morphologies, occurred earlier for astrocytes (53). One main characteristic of TBI associated diffuse axonal injury is the axonal disruption caused by shearing forces. This pathophysiology is present in the weight drop models of TBI that use the gravitational forces of a free falling weight to produce a mix of focal and diffuse brain injury. Typical pathological changes include axonal swelling, axoplasmic ovoid retraction balls and expression of amyloid beta peptides (51). In our study, the number and size of protoplasmic astrocytes increased in response to injury and swelling after TBI. The histopathological features appearing during the acute phase of TBI included shrinkage and swelling of the neuronal soma, as well as swelling of astrocytes.

Reactive gliosis is an early event that occurs after a variety of insults to the CNS. Diffuse TBI can lead to mild or moderate diffuse astrogliosis without obvious scar formation, in which reactive astrocytes hypertrophy and upregulate gene expression, including GFAP, but in which there is little or no loss of individual astrocyte domains. In rats, gliosis is detectable 24 hours after a lesion, and reaches a maximum response by 3-4 days $(23,46,54)$. In the current study, gliosis was detected in the gray matter particularly adjacent to the sites with severe cortical hemorrhage and vasogenic edema. In addition, the hypertrophic protoplasmic astrocytes and remarkable immunoreactive extensions were scattered diffusely throughout the perilesional cortical injury area. Appearing to involve all astrocytes in the area, these changes are consistent with classic astrocytic hypertrophy in response to local injury.

GFAP is the major protein of glial intermediate filaments in astrocytes. It has been proposed as a specific marker for assessing astrocytic response to injury. An increase in GFAP expression is a cardinal feature of many pathological conditions of the CNS and astrocytes $(15,57)$. Increasing numbers of GFAP (+) astroglial cells following TBI have been described in several experimental studies in animals. These data correlate with an elevation in GFAP gene expression (mRNA) that could be detected in response to mild cortical contusions in animals $(15,26)$. In the current study, GFAP of the immunohistochemical analysis demonstrated that the count of astrocytes and thickness of the extensions increased in the perilesional cortex areas. GFAP was weakly expressed in the normal brain tissue, while in the traumatic groups, gradually increasing GFAP (+) cell count was strong throughout the perilesional cortex area, which correlated with the increased weight particularly in the group 4.

\section{Is CCT Absolutely Necessary for the Diagnosis of Head Trauma?}

Patients presenting at the emergency medicine department due to head trauma are currently evaluated with physical examination, CCT and GCS (16). CCT is an important device for the diagnosis of patients with head trauma. However, the indications of CCT are still debated with respect to the diagnosis of patients with minor head trauma $(10,20,21,24)$. GCS offers limited results for the evaluation of patients who are sedated and intubated under emergency conditions. Used for diagnosis and treatment of subjects with head trauma, CCT is clearly indicated in highly probable intra-cranial injury conditions such as loss of consciousness, findings related with fracture of skull base, progressive neurological deficit, compression fracture of skull, open skull injuries and penetrating head trauma (38). GCS is used as a surrogate marker for the presence of TBI and to score the severity of TBI (46). Most clinicians recommend a CCT scan when any finding determined leading to suspect TBI (nausea and vomiting) or when the GCS score is equal to or below $13(43,55)$. Minor head trauma accounts for a substantial part of all cases with head trauma. CCT has high sensitivity in terms of diagnosing the TBI, but it is not useful in all children with minor head trauma, considering the high cost and the time and resources required. The incidence of intra-cranial pathologies that are diagnosed with CCT ranges between $3 \%$ and $6 \%$ in patients with minor head trauma $(11,13,35,48)$. The studies demonstrate that minor head trauma accounts for $60-95 \%$ of the pediatric population presenting to the emergency department due to head trauma $(10,20,21,24)$. Clinicians order CCT at rate of $5-50 \%$, among all diagnostic imaging scans for subjects with 
Cikriklar HI. et al: Effectiveness of GFAP in Traumatic Brain Injury

minor head trauma (41). However, there are still contradictory results in the literature on the diagnostic use of CCT for this group of patients $(17,49)$. There are views advocating CCT for almost all subjects with minor head trauma on one hand, and there are authors reporting that CCT should be electively used considering the clinical history and particular findings of the neurophysiological examination or even that this imaging study should never be used on the other hand $(17,31,49)$. Therefore, the target should be minimized use of imaging studies when efforts are being made to diagnose treatable TBI in children with minor head trauma (56).

Miller et al. (35) reported that loss of consciousness and amnesia could not be indicator for severe intracranial trauma. The indicators of intracranial trauma are not clear in children aged below two years. Neurological abnormality, variable mental state, scalp anomalies (contusion, laceration, abrasion and cephalic hematoma) and vomiting are regarded as best indicators. Hematoma of scalp is regarded as a useful indicator for demonstrating underlying fractures particularly in infants with minor head trauma, who are aged below 1 year, and radiological imaging is recommended for those patients (12). However, some studies reported that half of the patients with TBI may not demonstrate specific findings, such as vomiting, seizure or loss of consciousness, and therefore, those findings have weak sensitivity and specificity with respect to the diagnosis of intra-cranial injury (43). Wang et al. (49) reported that the history of loss of consciousness is a weak indicator of intra-cranial injury in patients with minor head trauma. CCT scan required sedation, leading to many risks including hypoxia, apnea, change of consciousness state, aspiration and even the indication of endotracheal intubation $(8,40)$.

\section{CONCLUSION}

CCT results are within normal ranges in almost $94-97 \%$ of the patients with minor head trauma, resulting in unnecessary use of CCT in many patients. Therefore, alternative diagnostic methods are required for the diagnosis of minor head trauma particularly in pregnant women and the pediatric population. We determined that the number of apoptotic cells and particularly the number of GFAP $(+)$ protoplasmic astrocytes at the perilesional region of the cortex increases in association with the increased serum GFAP level as long as the severity of trauma increases. Therefore, serum GFAP concentration can be used as a marker of the severity of head trauma and TBI. However, more animal studies are required to reflect this result in the clinical practice.

\section{- REFERENCES}

1. Ananiadoua OG, Drossos GE, Bibou KN, Palatianos GM, Johnson EO: Acute regional neuronal injury following hypothermic circulatory arrest in a porcine model. Interact Cardiovasc Thorac Surg 4:597-601, 2005

2. Ates O, Cayli S, Altinoz E, Gurses I, Yucel N, Sener M, Kocak A, Yologlu S: Neuroprotection by resveratrol against traumatic brain injury in rats. Mol Cell Biochem 294:137-144, 2007
3. Beaudin M, Saint VD, Quimet A, Mercier C, Crevier L: Clinical algorithm and resource use in the management of children with minor head trauma. J Pediatr Surg 42:849-852, 2007

4. Brenner DJ: Estimating cancer risks from pediatric CT: Going from the qualitative to the quantitative. Pediatr Radiol 32:228231, 2002

5. Brenner DJ, Hall EJ: Computed tomography-an increasing source of radiation exposure. N Engl J Med 357:2277-2284, 2007

6. Cernak I, Vink R, Zapple DN, Cruz MI, Ahmed F, Chang T, Fricke ST, Faden Al: The pathobiology of moderate diffuse traumatic brain injury as identified using a new experimental model of injury in rats. Neurobiol Dis 17:29-43, 2004

7. Conroy BP, Grafe MR, Jenkins LW, Vela AH, Lin CY, DeWitt DS, Johnston WE: Histopathologic consequences of hyperglycemic cerebral ischemia during hypothermic cardiopulmonary bypass in pigs. Ann Thorac Surg 71:13251334, 2001

8. Da Dalt L, Marchi AG, Laudizi L, Crichiutti G, Messi G, Pavanello L, Valent F, Barbone F: Predictors of intracranial injuries in children after blunt head trauma. Eur $\mathrm{J}$ Pediatr 165:142-148, 2006

9. Galea E, Dupouey P, Feinstein DL: Glial fibrillary acidic protein mRNA isotypes: Expression in vitro and in vivo. J Neurosci Res 41:452-461, 2001

10. Goodwin V, Evans RJ: The management of children with head injuries. Curr Pediatrics 11:420-432, 2001

11. Greenes DS, Schultman SA: Clinical indicators of intracranial injury in head injuried infants. Pediatrics 104:861-867, 1999

12. Greenes DS, Schultman SA: Clinical significance of scalp abnormalities in asymptomatic head-injured infants. Pediatr Emerg Care 17:88-92, 2001

13. Gruskin KD, Schutzman SA: Head trauma in children younger than 2 years: Are there predictors for complications? Arch Pediatr Adolesc Med 153:15-20, 1999

14. Gürses D, Sarıoğlu BA, Başkan M, Herek Ö, Kılıç İ: Epidemiologic evaluation of trauma cases admitted to a pediatric emergency service epidemiologic evaluation of trauma cases admitted to a pediatric emergency service epidemiologic evaluation of trauma cases admitted to a pediatric emergency service epidemiologic evaluation of trauma cases admitted to a pediatric emergency service. Ulus Travma Derg 8(3):156159, 2002

15. Hausmann R, Rieb R, Fieguth A, Betz P: Immunohistochemical investigations on the course of astroglial GFAP expression following human brain injury. Int J Legal Med 113(120):70-75, 2000

16. Hoffmann M, Lefering R, Rueger JM, Kolb JP, Izbicki JR, Ruecker AH, Rupprecht M, Lehmann W; Trauma Registry of the German Society for Trauma Surgery: Pupil evaluation in addition to Glasgow Coma Scale components in prediction of traumatic brain injury and mortality. Br J Surg 99(1):122-130, 2012

17. Holmes JF, Baier ME, Derlet RW: Failure of the Miller criteria to predict significant intracranial injury in patients with a Glasgow Coma Scale score of 14 after minor head trauma. Acad Emerg Med 4:788-792, 1997 
18. Huang W, Chen Y, Shohami E, Weinstock M: Neuroprotective effect of rasagiline, a selective monoamine oxidase-B inhibitor, against closed head injury in the mouse. Eur $\mathrm{J}$ Pharmacol 366:127-135, 1999

19. Isaksson J, Hillered L, Olsson Y: Cognitive and histopathological outcome after weight-drop brain injury in the rat: Influence of systemic administration of monoclonal antibodies to ICAM-1. Acta Neuropathol 102:246-256, 2001

20. Işık HS, Bostancı U, Yıldız Ö, Özdemir C, Gökyar A: Retrospective analysis of 954 adult patients with head injury: An epidemiological study. Ulus Travma Acil Cerrahi Derg 17(1):46-50, 2011

21. Işık HS, Gökyar A, Yıldız Ö, Bostancı U, Özdemir C: Pediatric head injuries, retrospective analysis of 851 patients: An epidemiological study. Ulus Travma Acil Cerrahi Derg 17(2):166-172, 2011

22. Johnson VE, Stewart W, Smith DH: Traumatic brain injury and amyloid- $\beta$ pathology: A link to Alzheimer's disease? Neuroscience 11:361-370, 2010

23. Kalayci M, Unal MM, Gul S, Acikgoz S, Kandemir N, Hanci V, Edebali N, Acikgoz B: Effect of coenzyme $Q_{10}$ on ischemia and neuronal damage in an experimental traumatic brain-injury model in rats. BMC Neurosci 12:75, 2011

24. Karasu A, Sabancı PA, Cansever T, Hepgül KT, İmer M, Dolaş I, Taviloglu K: Epidemiological study in head injury patients. Ulus Travma Acil Cerrahi Derg 15(2):159-163, 2009

25. Kaya SS, Mahmood A, Li Y, Yavuz E, Goksel M, Chopp M: Apoptosis and expression of p53 response proteins and cyclin D1 after cortical impact in rat brain. Brain Res 818:2333, 1999

26. Kochanek PM, Berger RP, Bayir H, Wagner AK, Jenkins LW, Clark RS: Biomarkers of primary and evolving damage in traumatic and ischemic brain injury: Diagnosis, prognosis, probing mechanisms, and therapeutic decision making. Curr Opin Crit Care 14:135-141, 2008

27. Kocsis JD, Tessler A: Pathology of blast-related brain injury. J Rehabil R D 46(6):667-672, 2009

28. Lafuente JV, Mitre B, Argandon EG: Spatio-temporal distribution of apoptosis and the modulators thereof following a cortical microinfarct in rat brain. Neurosci Res 57:354-361, 2007

29. Li F, Liu KF, Silva MD, Meng X, Gerriets T, Helmer KG, Fenstermacher JD, Sotak CH, Fisher M: Acute postischemic renormalization of the apparent diffusion coefficient of water is not associated with reversal of astrocytic swelling and neuronal shrinkage in rats. AJNR Am J Neuroradiol 23:180188, 2002

30. Lin HW, Basu A, Druckman C, Cicchese M, Krady JK, Levison, SW: Astrogliosis is delayed in type 1 interleukin-1 receptor-null mice following a penetrating brain injury. J Neuroinflammation 3:15, 2006

31. Livingston DH, Lavery RF, Passannante MR, Skurnick JH, Baker S, Fabian TC, Fry DE, Malangoni MA: Emergency department discharge of patients with a negative cranial computed tomography scan after minimal head injury. Ann Surg 232(1):126-132, 2000
32. Lumpkins KM, Bochicchio GV, Keledjian K, Simard JM, McCunn M, Thomas ST: Glial fibrillary acidic protein is highly correlated with brain injury. J Trauma 65:778-784, 2008

33. Lundberga J, Karimib M, Gerttena C, Holminc S, Ekstromb TJ, Nordqvist ACS: Traumatic brain injury induces relocalization of DNA-methyltransferase 1. Neurosci Lett 457:8-11, 2009

34. Marmarou A, Foda MA, van den Brink W, Campbell J, Kita $H$, Demetriadou K: A new model of diffuse brain injury in rats. Part I: Pathophysiology and biomechanics. J Neurosurg 80(2):291-300, 1994

35. Miller EC, Derlet RW, Kinser D: Minor head trauma: Is computed tomography always necessary? Ann Emerg Med 27:290-294, 1996

36. Mirzai H, Yağıı N, Tekin I: Epidemiologic and clinical features of cases applying to Celal Bayar University emergency unit with head trauma. Ulus Travma Acil Cerrahi Derg 11(2):146152, 2005 (in Turkish)

37. Missler U, Wiesmann M, Wittmann G, Magerkurth O, Hagenstrom $\mathrm{H}$ : Measurement of glial fibrillary acidic protein in human blood: Analytical method and preliminary clinical results. Clin Chem 45:138-141, 1999

38. Olshaker JS, Whye DPW: Head trauma. Emerg Med Clin North Am 11:165-186, 1993

39. Pelinka LE, Kroepfl A, Leixnering M, Buchinger W, Raabe A, Redl H: GFAP versus S100B in serum after traumatic brain injury: Relationship to brain damage and outcome. $\mathrm{J}$ Neurotrauma 21(11):1553-1556, 2004

40. Reed MJ, Browning JG, Wilkinson AG, Beattie T: Can we abolish skull X-rays for head injury? Arch Dis Child 90: 859864,2005

41. Quayle KS: Minor head injury in the pediatric patient. Pediatr Clin North Am 46: 1189-1199, 1999

42. Savitsky EA, Votey SR: Current controversies in the management of minor pediatric head injuries. Am J Emerg Med 18: 96-101, 2000

43. Schutzman SA, Greenes DS: Pediatric minor head trauma. Ann Emerg Med 20: 65-74, 2001

44. Shojo H, Kibayashi K: Changes in localization of synaptophysin following fluid percussion injury in the rat brain. Brain Res 1078:198-211, 2006

45. Silva DS, Brito JNPO, Ibiapina JO, Lima MFMB, Medeiros ARGV, Queiroz BH, Paiva AL, Guedes VO: Closed head injury in rats. Histopathological aspects in an experimental weight drop model. Acta Cir Bras 27(4):290-294, 2012

46. Sofroniew MV, Vinters HV: Astrocytes: Biology and pathology. Acta Neuropathol 119:7-35, 2010

47. Stein SC, Ross SE: Mild head injury: A plea for routine early CT scanning. J Trauma 33: 11-13, 1992

48. Türedi $S$, Hasanbașoğlu $A$, Gündüz $A$, Yandı M: Clinical decision instruments for CT scan in minor head trauma. $J$ Emerg Med 34: 253-259, 2008

49. Wang MY, Griffith P, Sterling J, McComb JG, Levy ML: A prospective population-based study of pediatric trauma patients with mild alterations in consciousness (Glasgow Coma Scale score of 13-14). Neurosurgery 46:1093-1099, 2000 
50. Weissenberger CA, Siren AL: Experimental traumatic brain injury. Exp TransI Stroke Med 2(1):16, 2010

51. Weissenberger CA, Varrallyay C, Raslan F, Kleinschnitz C, Siren AL: An experimental protocol for mimicking pathomechanisms of traumatic brain injury in mice. Exp Transl Stroke Med 4:1-5, 2012

52. Wiesmann M, Steinmeier E, Magerkurth O, Linn J, Gottmann $\mathrm{D}$, Missler U: Outcome prediction in traumatic brain injury: Comparison of neurological status, CT findings and blood levels of S100B and GFAP. Acta Neurol Scand 121:178-185, 2010

53. Williams AJ, Wei HH, Dave JR, Tortella FC: Acute and delayed neuroinflammatory response following experimental penetrating ballistic brain injury in the rat. $\mathrm{J}$ Neuroinflammation $4: 17,2007$
54. Woiciechowsky C, Schöning B, Stoltenburg-Didinger G, Stockhammer F, Volk HD: Brain-IL-1 beta triggers astrogliosis through induction of IL-6: Inhibition by propranolol and IL-10. Med Sci Monit 10(9):BR325-330, 2004

55. Woodcock RJ, Davis PC, Hopkins KL: Imaging of head trauma in infancy and childhood. Semin Ultrasound CT MR 22:162182, 2001

56. Woolard DJ, Terndrup DE: Sedative-analgesic agent administration in children: Analysis of use and complications in the emergency department. J Emerg Med 12:435-461, 1994

57. Yu HM, Yuan TM, Gu WZ, Li JP: Expression of glial fibrillary acidic protein in developing rat brain after intrauterine infection. Neuropathology 24: 136-143, 2004

58. Zurek J, Fedora M: Dynamics of glial fibrillary acidic protein during traumatic brain injury in children. J Trauma 71(4):854859, 2011 